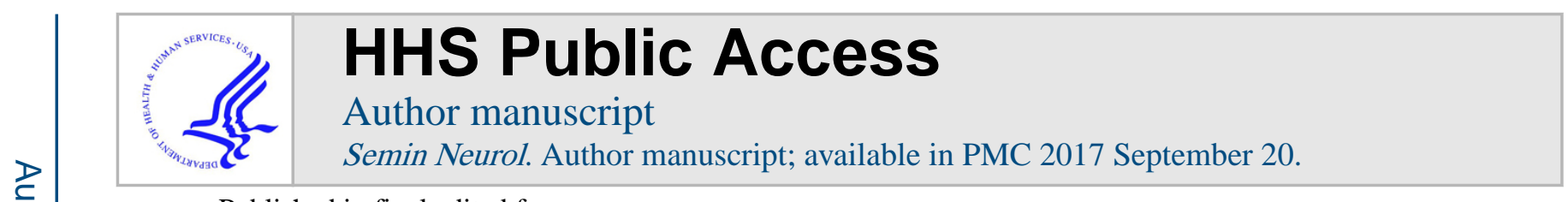

Published in final edited form as:

Semin Neurol. 2009 September ; 29(4): 406-418. doi:10.1055/s-0029-1237113.

\title{
Sleep and Headache
}

\author{
K.C. Brennan, M.D. ${ }^{1}$ and Andrew Charles, M.D. ${ }^{1}$ \\ ${ }^{1}$ Headache Research and Treatment Program, Department of Neurology, David Geffen School of \\ Medicine at UCLA, Los Angeles, California
}

\begin{abstract}
There is a strong interaction between sleep and headache. Sleep and headache disorders overlap epidemiologically, and share elements of anatomy and physiology. Perhaps as a result, their treatment is often mutually interdependent. Despite this, headache and sleep disorders tend to be treated separately, by different subspecialties of neurology. The headache disorders and their relationship to sleep, the commonalities of headache and sleep pathophysiology, and headache disorders that are particularly susceptible to sleep modulation (and vice versa) are reviewed. Practical management advice for sleep-modulated headaches is provided.
\end{abstract}

\section{Keywords}

Headache; sleep; migraine; arousal

The headache disorders are strongly modulated by sleep, and the sleep disorders are frequently characterized by headache. Despite this, they tend to be treated by physicians from different subspecialties, with divergent training and clinical priorities, meaning that they are often not considered together in treatment decisions. In addition to their clinical overlap, headache and sleep disorders both involve disruption of highly conserved brainstem and diencephalic networks that have homeostatic functions; as such, they share common pathways that may interact on multiple levels. An understanding of either set of disorders will be incomplete without knowledge of their shared anatomy and physiology.

The pathophysiologic commonalities between the sleep disorders and headaches will be discussed first, followed by a discussion of some of the disorders individually. This will be followed by a section on patient management. As several recent reviews have expertly covered the shared epidemiology of sleep and headache disorders, ${ }^{1-5}$ we refer the reader to these for details.

Address for correspondence and reprint requests: K.C. Brennan, M.D., Headache Research and Treatment Program, Department of Neurology, David Geffen School of Medicine at UCLA, 635 Charles E. Young Drive South, Neuroscience Research Building, Room 555a, Los Angeles, CA 90095 (kbrennan@ mednet.ucla.edu). 


\section{ANATOMY AND PHYSIOLOGY OF SLEEP AND HEADACHE}

\section{Sleep and Arousal}

The brainstem and diencephalon are central to sleep and arousal. Although the sleep cycle has been more extensively discussed elsewhere in this volume, ${ }^{6,7}$ we review certain key concepts here to highlight areas of possible interaction between sleep and headaches.

AROUSAL-The main mediators of arousal are the cholinergic and monoaminergic nuclei of the brainstem and basal fore-brain, which interact with state-generating centers in the thalamus and hypothalamus. Two main arousal streams have been identified. ${ }^{6,7}$ The first, arising from the pedunculopontine nucleus and the laterodorsal tegmentum, projects to the thalamus. This is excitatory to thalamic neurons, maintaining membrane potential at levels that prevent them from entering a sleep-associated bursting mode. The second arousal stream originates more diffusely in the basal forebrain and the brainstem, and projects to the hypothalamus. The basal forebrain contains cholinergic nuclei. From the brainstem come the monoaminergic nuclei, the noradrenergic locus ceruleus, the serotonergic dorsal and median raphe nuclei, dopaminergic neurons of the ventrolateral periaqueductal gray, and histaminergic neurons of the tuberomammillary nucleus. These predominantly excitatory projections converge on the lateral hypothalamic area (LHA), which is the primary source of orexin, a key component of the arousal switching mechanism that has also been implicated in pain processing (see below).

SLEEP-As might be expected, inhibition of the nuclei involved in arousal is part of sleep regulation. The arousal-associated tuberomammillary nucleus, locus ceruleus, and dorsal and median raphe are inhibited by the ventrolateral preoptic nucleus (VLPO) of the hypothalamus, via gamma amino butyric acid (GABA) and galanin. Sleep-promoting VLPO activity is activated by adenosine, which is thought to be an endogenous somnogen.

Adenosine is generated from adenosine triphosphate (ATP), and accumulates over the day, likely providing part of the homeostatic drive for sleep. ${ }^{8}$ As well as activating the VLPO, adenosine inhibits the arousal-associated cholinergic nuclei of the basal forebrain.

CIRCADIAN CONTROL-The circadian sleep drive, unlike the homeostatic drive, is intrinsic and can function independently of activity. The neurons of the suprachiasmatic nucleus (SCN) are the pacemakers of the system, with an intrinsic 24-hour activity rhythm that is aligned with the day/night cycle via retinal inputs during the day and melatonin from the pineal gland at night.

The SCN is connected to hypothalamic sleep-related nuclei (VLPO and LHA) indirectly, through nuclei involved in complementary forms of homeostatic regulation, such as corticosteroid hormone release (dorsomedial hypothalamus [DMH]) and thermoregulation dorsal subparventricular zone (dSPZ). Similarly, a strong indirect connection via DMH to locus ceruleus has been identified. ${ }^{9}$ These indirect connections from SCN to arousal and sleep centers are thought to exist to ensure that different inputs relevant to the sleep wake cycle are integrated. ${ }^{7}$ They also allow hypothalamic sleep and arousal output to be coordinated with other autonomic output. 
SLEEP-WAKE AND NREM-REM TRANSITIONS-The transition from wake to sleep and vice versa is highly regulated, and conditions in which characteristics of the sleep and wake states are not properly partitioned (rapid eye movement [REM] behavior disorder, narcolepsy) are considered pathologic. To understand the transition, Saper and colleagues have advanced the concept of the flip-flop switch, ${ }^{7}$ an engineering term for a system which heavily favors one or the other of two states, but disfavors any transitional mode between the two. There is strong evidence that the mutually interconnected networks promoting sleep and wakefulness function in this manner.

The wake-promoting monoaminergic and cholinergic nuclei have mutually inhibitory reciprocal connections with the ventrolateral preoptic nucleus in the hypothalamus. This type of connection is consistent with a flip-flop switch, as increased activity in one of the opposed arms increases inhibition of the other arm. Like the sleep/wake transition, the transition between non-REM (NREM) and REM sleep is also both rapid and fundamental, and there is recent evidence that this transition also involves a flip-flop switch. ${ }^{10}$ Mutually inhibitory connections consistent with such a switch have been identified between a REMon region in the sublaterodorsal and preceruleus regions (SLD/PC; in the mesopontine tegmentum in the vicinity of the locus ceruleus) and a REM-off region in the ventrolateral periaqueductal gray and lateral pontine tegmentum (vlPAG/LPT; in the pontine tegmentum). The vlPAG/LPT REM-off region contains orexin-2 receptors, and receives excitatory projections from the orexinergic neurons of the lateral hypothalamic area, which are active during wakefulness, but inactive during REM sleep. As we will see, the vlPAG has also been shown to be active in pain modulation.

\section{Headache}

Like sleep, nociception involves a complex network of interacting brain structures with distinct physiologic and pharmacologic properties. Although recent work has shown that nociceptive inputs are indeed "labeled lines" that are consistent with specific pathways, and are not merely subsets of somatic sensation, it is also clear that these inputs are part of a multiply redundant matrix that includes significant behavioral and autonomic components. ${ }^{11-13}$ Nociception and sleep are both closely linked with mood and affect as well as with homeostatic autonomic function. Unlike sleep, however, pain has much less reliably quantifiable measures. This is particularly true for headache, which has few definitively measurable physiologic correlates. As a consequence, headache disorders are more difficult to investigate, and less is known about their anatomic and physiologic substrates.

ANATOMY - The principal innervation of the cranium and its contents comes from the trigeminal nerve (with contributions from glossopharyngeal, vagus, and cervical roots $\mathrm{C} 1-$ $\mathrm{C} 3$ around the ear, occiput, and posterior fossa). After synapsing on the relevant sensory ganglia (trigeminal ganglion, superior and inferior ganglia of the glossopharyngeal and vagus nerves, and $\mathrm{C} 1-\mathrm{C} 3$ dorsal root ganglia), all of these afferents converge on the trigeminal nucleus caudalis (TNC), the principal brainstem nucleus subserving pain and temperature sensation in the head and neck. 
The innervation of the intracranial contents is distinct from other parts of the body. The brain parenchyma proper (with the possible exception of the periaqueductal gray ${ }^{14}$ and the insula ${ }^{15}$ ) does not sense pain; this allows for awake neurosurgical procedures. However, the cerebral arteries and dural sinuses are heavily innervated with the a-delta and c-fibers which transmit pain. The pia, dura, and vessels of the anterior and middle cranial fossae are innervated by the first (V1) division of the trigeminal nerve through the trigeminal ganglion, whereas sensation from the posterior fossa is additionally innervated from cranial nerve (CN) X (superior ganglion) and C1-C3 (dorsal root ganglia). ${ }^{16,17}$

From the TNC, pain and temperature information passes up the trigeminal lemniscus to the ventral posteromedial thalamus (VPM) and then to the somatosensory cortex. However, trigeminal nucleus caudalis efferents also supply the insular and limbic cortices, which are thought to process visceral and affective aspects of pain, respectively. ${ }^{18}$ These efferents pass through a highly interconnected brainstem and diencephalic circuit, which interacts at multiple levels with autonomic control centers. ${ }^{12,13}$ The TNC also has direct relays to the hypothalamus via the trigeminohypothalamic tract. ${ }^{19}$ Craniofacial pain both modulates, and is modulated by, homeostatic systems. It is thus not surprising that so many of the headache disorders are characterized by autonomic and affective symptoms.

TRIGEMINOVASCULAR AND TRIGEMINO-AUTONOMIC REFLEXES-Trigeminal afferents also have their own effector functions, which can be independent of higher brainstem modulation. Trigeminal stimulation, either over cerebral vessels, along the trigeminal nerve, or in the trigeminal ganglion, causes antidromic release of substance $\mathrm{P}$, neurokinins, and calcitonin gene-related peptide (CGRP) from the afferent terminals (reviewed in reference 20). These mediators dilate dural and cortical surface vessels; increase the permeability of dural vessels resulting in plasma protein extravasation; and cause further depolarization of the very nerves that released them, creating a positive feedback loop. This feedback can be amplified by activation of parasympathetic efferents, likely via the superior salivatory nucleus, which perpetuates the response. This integrated response is referred to as the trigemino-autonomic reflex. ${ }^{20}$

BRAINSTEM AND DIENCEPHALIC PROCESSING-It has yet to be determined which of the peripheral and central components of craniofacial pain are primarily involved in the generation of different types of headache disorders; however, it is likely at higher brainstem and diencephalic circuit levels that the pain and sleep systems interact. Collaterals from neurons in the TNC synapse on the nucleus of the solitary tract (NTS) and the parabrachial nucleus (PBN). The NTS is the principal nucleus for viscerosensation, and is thus involved in cardiovascular, respiratory, and gastrointestinal reflex loops. The PBN has similar viscerosensitive functions, but is a higher level regulator, and communicates to a greater extent than the nucleus of the solitary tract visceral information to the hypothalamus, thalamus, and cortex. ${ }^{12}$

Via collaterals to the nucleus of the solitary tract and PBN, TNC neurons are thus in contact with all components of central autonomic control. These include networks for modulation of pain, arousal and sleep, sympathetic and parasympathetic outflow, and neuro-endocrine function. In turn, by virtue of entry into these networks, nociceptive information becomes 
amenable to feedback from other modalities. It is at these network levels that sleep and headaches are likely connected.

DESCENDING PAIN CONTROL-As might be expected, the trigeminal nociceptive system interacts at multiple levels with the descending pain control system. A first element in this circuit is the rostroventromedial medulla (RVM), ${ }^{21}$ a relay in descending modulation of pain which can have both facilitatory and inhibitory effects. Facilitatory cells in the RVM have been shown to be involved in the allodynia associated with neuropathic pain, and there are preliminary reports that the RVM may have a similar role in the allodynia of migraine. ${ }^{22}$ A second element is the series of raphe nuclei, most prominently the medullary raphe magnus and pallidus. These serotonergic nuclei project to the dorsal horn of the spinal cord and brainstem, activating inhibitory interneurons which reduce pain afferent activity. A third element is the noradrenergic locus ceruleus (LC) in the pons, which also projects to the dorsal horn and inhibits pain afferent activity. As above, the LC and raphe nuclei are also involved in arousal, and inhibition of REM sleep.

Further rostral is the periaqueductal gray (PAG). Stimulation of the PAG can induce anesthesia in humans and experimental animals. Though often referred to as a homogeneous unit, the PAG has multiple cell columns which can entrain opposite behaviors. For example, stimulation of the ventrolateral PAG (vlPAG) in cat causes motor quiescence and decreased blood pressure, whereas stimulation of the lateral PAG causes a flight reaction including increased blood pressure. ${ }^{12}$ This coordinated behavior reveals that the PAG is at a higher level of organization than the RVM, locus ceruleus, or raphe nuclei; indeed, it sends processes to each of these regions. PAG projections to the LC and raphe nuclei are what entrain the dorsal horn analgesia effects of these lower nuclei.

The vlPAG is a particularly rich region for interaction between sleep and headaches. First, activity in that region causes motor quiescence and other behaviors surprisingly similar to those seen in migraine attacks. ${ }^{23}$ Second, the vlPAG is a REM-off region, innervated by orexinergic afferents from the lateral hypothalamic area. ${ }^{7}$ Cluster headache, migraine, paroxysmal hemicrania, and hypnic headache have all shown an association with arousal from REM sleep and/or derangements in REM (see below). Third, recent work has demonstrated an antinociceptive role for neurons in the vlPAG, with direct orexin stimulation of vlPAG neurons inhibiting nociceptive activity in the trigeminal nucleus caudalis. ${ }^{24}$ This builds on prior work showing that systemic orexin agonists reduced several indices of trigeminovascular activation. ${ }^{25,26}$ Fourth, human structural and functional imaging studies in migraine have shown alterations of the rostrodorsal pons, particularly regions consistent with periaqueductal gray, but also consistent with the dorsal raphe or locus ceruleus. ${ }^{27-29}$ An influential PET study ${ }^{27}$ showed that rostrodorsal pontine activation actually coincided with a spontaneous migraine attack. Finally, and perhaps most convincingly, it has been known for some time that stimulation of the periaqueductal gray (or, again, the immediately adjacent DRN or LC) in humans can bring on headaches indistinguishable from migraine. ${ }^{14,30}$

HYPOTHALAMUS-There is probably no "pain control" center per se in the hypothalamus; rather multiple areas are involved in coordinating patterned responses, of 
which pain modulation is a constituent part. To a greater extent than the PAG, the hypothalamus is a complex pattern generator, orchestrating the activity of lower centers to generate a homeostatic response. ${ }^{12}$

Multiple imaging studies in different types of primary headaches have identified either activation or structural abnormality in regions consistent with posterior hypothalamus during the headache phase. This pattern has been particularly prominent in the trigeminal autonomic cephalalgias (TACs), including cluster headache, ${ }^{31}$ paroxysmal hemicrania, ${ }^{32}$ and short-lasting unilateral neuralgiform headache with conjunctival injection and tearing (SUNCT), ${ }^{33,34}$ and was thought to be specific to these disorders. However, a recent study has shown posterior hypothalamic activation (in addition to pontine activation) during migraine,${ }^{35}$ suggesting that brainstem and hypothalamic activation may be common to all the primary headache disorders, and even craniofacial pain in general. ${ }^{36}$

The hypothalamus packs myriad, often mutually exclusive functions into a very small region, and functional imaging does not yet have the ability to conclusively distinguish even large brainstem nuclei, let alone subnuclei of the hypothalamus. The region referred to as "posterior hypothalamus" on structural and functional imaging studies is much broader than the histologically defined group of nuclei. However, injection of morphine into the posterior hypothalamic area can cause profound analgesia, ${ }^{37}$ suggesting a role in pain modulation. Posterior hypothalamic stimulation is effective in alleviating intractable cluster headache. ${ }^{38}$

Interestingly, both the posterior hypothalamic area and the immediately adjacent lateral hypothalamic area and DMH (which could easily be contained in the broad areas of activation seen on functional imaging) contain orexinergic neurons. A recent study has shown that hypothalamic orexinergic neurons are involved in the descending inhibition of pain which occurs during stress-induced analgesia. ${ }^{39}$ Orexinergic neurons have been implicated in both narcolepsy (via their selective loss) ${ }^{40}$ and in modulation of nociceptive activity in the trigeminal nucleus caudalis (via activity in the vlPAG). ${ }^{24}$ As will be seen below, narcolepsy may be associated with an increased prevalence of migraine and tensiontype headache. And though so far there is no direct evidence, the circadian nature of several headache disorders strongly suggests involvement of the SCN. Thus, though there is likely not a specific "headache generator" in the hypothalamus (nor, given its function, would one expect such a center), it is possible that dysfunctional hypothalamic activity contributes to both altered sleep/wake function as well as altered pain processing via its orexinergic neurons.

Fig. 1 summarizes the shared anatomy of headache and sleep.

\section{Adenosine}

Adenosine is a ubiquitous compound with myriad roles in the body. A product of the degradation of ATP, adenosine is primarily a local signaling molecule with inhibitory, vasodilatory, and cytoprotective roles, whose activity is linked (via ATP) to energy metabolism. ${ }^{41}$ Adenosine has four receptor subtypes, A1, A2A, A2B, and A3, distributed in different anatomic locations, sometimes with opposite functions. So to speak of "actions of adenosine" is meaningless without qualification by tissue type and receptor subtype. That 
said, both sleep and pain, and their respective disorders, appear to rely on adenosinergic activity for some of their functions.

Adenosine is most likely an endogenous somnogen, which accumulates with energy consumption during the day. ${ }^{42,43} \mathrm{An}$ area that appears particularly sensitive to adenosine concentrations is the basal fore-brain, whose cholinergic nuclei are involved in arousal. Basal forebrain cholinergic neurons have A1 and A2a receptors, and respond to increasing concentrations of adenosine with decreased activity. ${ }^{44}$ In opposite fashion, the sleeppromoting ventrolateral preoptic nucleus of the hypothalamus is excited by adenosine. Moreover, adenosine concentrations vary over the sleep-wake cycle, increasing with prolonged wakefulness, and decreasing with sleep, consistent with the kinetics of an endogenous somnogen. ${ }^{8}$ Adenosine is likely involved in slow wave sleep, as exogenous adenosine can precipitate slow wave sleep, and caffeine in humans attenuates the phenomenon (reviewed in reference 43). Recently, a mutation in adenosine deaminase (which degrades adenosine) was found, which significantly increases the duration and intensity of slow wave sleep. ${ }^{45}$

There is some evidence that adenosine may be relevant to the headache disorders as well, but the anatomy and physiology is complex. Adenosine activity at presynaptic A1 receptors in spinal cord is antinociceptive, ${ }^{46}$ and A1 knockout mice have an increased sensitivity to pain. ${ }^{47}$ Selective A1 agonists have been shown to inhibit trigeminal nociception in rodents, ${ }^{48}$ and in humans, A1 agonists reduce the nociception-specific blink reflex. ${ }^{49}$ Perioperatively, adenosine itself has been used as an adjunct or even a substitute for opiate analgesia, ${ }^{50}$ but it is not free of side effects, which include flushing and, interestingly, headache.

The other side of the coin is that activation of $\mathrm{A} 2 \mathrm{~A}$ receptors can induce pain, and $\mathrm{A} 2 \mathrm{~A}$ receptor knockout mice show hypoalgesia (reviewed in reference 51). Caffeine, an adenosine A1 and A2A antagonist, is an analgesic that is commonly used for all types of headache (excedrin contains $65 \mathrm{mg}$ of caffeine, equivalent to a cup of coffee). Caffeine withdrawal is a common cause of problematic headaches. ${ }^{52}$ Dipyridamole, a phosphodiesterase inhibitor and adenosine re-uptake inhibitor, has headache as its major side effect, and induces migrainelike headache in migraine patients. ${ }^{53}$ Finally exogenously administered adenosine can induce migraine. ${ }^{54}$

The apparently contradictory effects of adenosine are most likely due to its different roles at different locations and receptor subtypes. With this in mind, it is important to recall that adenosine is a vasodilator, via $\mathrm{A} 2 \mathrm{~A}$ receptors. And via $\mathrm{A} 1, \mathrm{~A} 2 \mathrm{~A}$, and $\mathrm{A} 3$ receptors, adenosine has been implicated in the neurogenic inflammation that is part of the trigeminovascular reflex (see above). ${ }^{55}$ In its role as an inhibitory neuromodulator, adenosine may prevent the excessive excitation that could lead to headache initiation or perpetuation. In its role mediating vasodilatation and neurogenic inflammation, it may activate the very trigeminovascular system that it inhibits downstream.

The data on adenosine levels during headache are sparse; however, two small studies have found $47 \%$ and $68 \%$ increases in plasma adenosine levels in migraineurs during the attack compared with control conditions. ${ }^{56,57}$ Whether these increases are causal, or epiphenomena 
of nociceptive activation, is of course an open question. But adenosinergic activity does appear to be involved in migraine. It was recently found that a polymorphism in an $\mathrm{A} 2 \mathrm{~A}$ receptor haplotype is associated with migraine with aura. ${ }^{58}$ Clearly, the role of adenosine in both headache and sleep disorders bears a great deal more research.

\section{Melatonin}

Melatonin is synthesized from serotonin by pinealocytes in the pineal gland. It is secreted nightly, its timing closely entrained by activity from the suprachiasmatic nucleus (SCN), which itself integrates incoming light information from the retinohypothalamic tract. High levels of blue light inhibit melatonin secretion, and low levels favor it. In conditions of natural lighting, melatonin secretion begins when daylight dims, peaks at midnight, and decreases in the later night hours. Thus, melatonin helps maintain the daily sleep-wake cycle. Melatonin is also involved in seasonal behavioral changes, for example in animals with seasonally dependent mating, probably via integration of changes in length of daylight. ${ }^{59}$

Given its prominent chronobiology—daily and seasonal—it is not surprising that cluster headache has shown alterations in melatonin secretion, with decreased peak and median melatonin secretion ${ }^{60-63}$ and a phase advance in timing of secretion ${ }^{60}$ during the cluster period. In addition, there was a disruption of the phase relationship between cortisol and melatonin, which normally is highly conserved. ${ }^{63}$

Reductions in plasma melatonin have also been seen in migraine patients, ${ }^{64}$ although a significant effect of concomitant affective disorders was also seen. When controlled for affective disorders, only females showed decreased peak melatonin levels. A follow-up on this female predilection showed significantly reduced peak urinary nocturnal melatonin in the luteal phase in patients with menstrually related migraine. ${ }^{65}$ As menstrual migraine generally occurs between the end of the luteal phase and the beginning of the subsequent cycle, these differences could be relevant. Melatonin secretion in migraine patients has also been shown to be more sensitive to light than in controls. ${ }^{66}$

Treatment with melatonin reduced headache frequency in episodic but not chronic cluster headache patients, in a placebo controlled trial. ${ }^{67}$ Other reports have been small and results have been mixed. There have been no placebo controlled trials of melatonin in migraine, but numerous observational studies and case reports support the possibility of an effect (reviewed in reference 68).

\section{Transgenic Models}

Basic neuroscience has been revolutionized by transgenic models of disease. The headache disorders are no exception to this. And very interestingly, these transgenic animals may have sleep phenotypes.

Recently, a family was identified with both familial migraine with aura and familial advanced sleep phase syndrome (FASPS), ${ }^{69}$ which appeared to be inherited in an autosomal dominant manner. On average, affected family members woke and went to sleep 3 to 4 hours earlier than their unaffected relatives, consistent with the FASPS phenotype seen in other 
kindreds. ${ }^{70}$ A mutation was identified from this family in the casein kinase $1 \delta(\mathrm{CK} 1 \delta)$ gene, which codes for a ubiquitously expressed serine/threonine kinase that is known to be involved in circadian clock regulation. ${ }^{71}$ Expressed in fly and in mouse, this mutation recapitulated a circadian phenotype.

Familial advanced sleep-phase syndrome is not generally perceived as a disease by patients; it was migraine with aura that brought the CK1 $\delta$ mutant family to medical attention. The existence of a transgenic mouse allowed investigation of the possibility of a migraine phenotype. CK1 $\delta$ transgenic mice showed a significantly lower threshold for cortical spreading depression compared with their wild-type littermates, ${ }^{72}$ suggesting that CK1 $\delta$ transgenics have an increase in cortical excitability, consistent with a susceptibility to migraine with aura. In addition, pial arteriolar dilatation during cortical spreading depression was significantly greater in transgenic animals, despite virtually identical baseline arteriolar diameters. This suggests that the neurovascular changes which link CSD and migraine pain $^{73}$ are also deranged. Further testing with a mouse model of allodynia ${ }^{74}$ demonstrated that $\mathrm{CK} 1 \delta$ mice do have alterations in nociceptive processing, with decreased mechanical and thermal pain thresholds compared with wild-type litter-mates in response to nitroglycerin injection.

CK1 $\delta$ transgenic mice appear to offer the first animal model of shared migraine and sleep pathology. However, an interesting corollary to these findings is evidence that established mouse migraine models may also have derangements of sleep. The R192Q strain of CACNA1A (FHM1) mice, which show reduced threshold for CSD, also show alterations in the sleep-wake cycle, with abnormal adjustment to phase shifts in the dark/light cycle. ${ }^{75}$ These findings, from a mouse generated from a completely different human mutation, suggest that circadian dysregulation, and perhaps alterations in the $\mathrm{SCN}$, may be common to migraine in general.

\section{THE SLEEP AND HEADACHE DISORDERS}

\section{Migraine}

Migraine includes a constellation of symptoms that may occur before, during, or after headache, (or even in the absence of headache). Some of these symptoms are referable to cerebral cortex, and include visual symptoms such as scintillations and scotoma, cortical sensory symptoms, language dysfunction, and other cognitive dysfunction. Other symptoms indicate changes in brainstem or diencephalic structures: prodromal symptoms of hunger and thirst, polyuria, and yawning; and ictal symptoms of vomiting, vertigo, flushing and pallor, and occasional conjunctival injection and tearing. Still others are not clearly localizable, such as light and sound sensitivity, fatigue, and mood changes.

Migraine has prominent chronobiologic features. The association with the menstrual cycle in females is well known. ${ }^{76}$ Less well-known are circa-septan patterns, with more frequent headaches on the weekend, and circannual patterns, with more frequent headaches in winter in Italy ${ }^{77}$ and in summer in northern Norway. ${ }^{78,79}$ 
There is good evidence for a circadian phenotype in migraine. All four studies examining the question found a periodicity to migraine occurrence, with a sinusoidal variation in frequency over the 24-hour cycle. ${ }^{80-83}$ Three of the four studies ${ }^{80-82}$ found a peak frequency in the morning hours. The fourth study found a peak at noon. ${ }^{83}$ The most common explanation of circadian periodicity in migraine involves the cycling of glucocorticoid and catecholamine levels, whether endogenously or as a result of work or activity. ${ }^{81-83}$ This is supported by work in humans showing elevated catecholamine levels in migraineurs who awoke with headache. ${ }^{84}$ But to date there has been no experimental data to evaluate this hypothesis.

The end of the sleep cycle, which generally occurs in the early morning hours, is notable for an increased fraction of REM sleep relative to NREM sleep. Dexter and Weitzman first suggested that migraine might arise from REM sleep, based on observations in three patients with nocturnal migraine. ${ }^{85}$ The data since then has been less clear-cut, with some studies finding an association of attacks with REM sleep,${ }^{84}$ others finding associations with other stages as well as REM ${ }^{86}$ and still others showing no association. ${ }^{87}$ Examination of interictal polysomnography has revealed increased ${ }^{88}$ as well as decreased ${ }^{89}$ or no difference in ${ }^{90,91}$ total REM in migraine. However, altered arousability parameters in interictal polysomnography have been found in both NREM and REM sleep of migraine patients, suggestive of impaired arousal mechanisms in nocturnal migraine. ${ }^{87,90,91}$ Interestingly, these findings are all suggestive of decreased arousability, especially the night before a migraine. ${ }^{87}$ Although this is counterintuitive considering the idea of migraine as a disorder of increased neural excitability, it suggests the possibility that specific sleep-stage findings are downstream of more generalized changes in arousal networks.

\section{Cluster Headache and Other Trigeminal Autonomic Cephalgias}

By its most basic clinical characteristics cluster headache shows an involvement of the regulators of circadian function. Cluster headache is intensely chronobiologically determined. Clusters of headache occur usually with a seasonal predilection. They are also usually exquisitely timed, at remarkably similar times of day. Moreover, $75 \%$ of cluster episodes occur between 9 PM and 10 AM, times more likely to be associated with sleep, ${ }^{92}$ and tend to occur 90 minutes after falling asleep. ${ }^{93}$

The circadian nature of cluster headache strongly suggests alterations in hypothalamic and brainstem circuits. Human functional imaging has shown hypothalamic activation during cluster headache compared with headache free periods, ${ }^{31,94}$ and voxel-based morphometry (VBM) has shown structural abnormalities in the posterior hypothalamus in cluster headache patients. ${ }^{95}$ Magnetic resonance spectroscopy revealed decreases in $\mathrm{N}$-acetyl aspartate (NAA), a marker which correlates with neuronal function. ${ }^{96}$ Deep brain stimulation (DBS) of the posterior hypothalamus is an effective treatment for intractable cluster headache. ${ }^{38}$

Cluster headache shows an association with REM sleep, ${ }^{97}$ as well as abnormalities in melatonin and cortisol secretion. ${ }^{63}$ It is difficult to interpret causality with these findingsfor example, they could be epiphenomena of pain or sleep dysfunction—but they strongly suggest derangement of hypothalamic function, which is consistent with the neuroimaging evidence. 
As with migraine, genetics may offer a promising complementary approach to the anatomy and physiology of cluster headache. Recently, a polymorphism in the orexin/hypocretin receptor 2 gene was found in a group of cluster headache patients. ${ }^{98,99}$ Given the role of orexin in both arousal and narcolepsy, and its possible role in pain modulation, this association is plausible from a pathophysiologic point of view.

Although they lack the distinct chronobiology of cluster headache, other trigeminal autonomic cephalalgias (specifically SUNCT ${ }^{33,100}$ and paroxysmal hemicrania ${ }^{101}$ ) have shown similar posterior hypothalamic activation to cluster headache. Unlike cluster headache, the other trigeminal autonomic cephalalgias tend not to have a strict circadian phenotype, although they do tend to have a seasonal predilection. ${ }^{102}$ The fact that these disorders show similar activation without circadian symptoms opens up the possibility that the hypothalamic activation seen is more associated with pain than with the sleep-wake cycle. The report of hypothalamic activation in migraine could also be consistent with this. Without more specific human functional imaging, this question is unlikely to be resolved conclusively. However, it is reasonable to conclude that diverse headache types appear to activate similar brainstem and diencephalic regions, consistent with known anatomy and physiology, suggesting distributed processing of both visceral pain and arousal.

\section{Hypnic Headache}

Hypnic headache is the one primary headache disorder that is described exclusively by its relation to sleep. It consists of a dull, holocephalic headache, lasting 10 to 180 minutes, that wakes the patient (often an elderly female) from sleep, generally 2 to 6 hours into the sleep cycle, around 1:00 to 3:00 AM. ${ }^{103}$ On average, events occur once a night, but they tend to occur a majority of nights (diagnostic criteria require 15 nights/month). Importantly, the headache is not associated with migrainous features like nausea, vomiting, and photo- and phonophobia; or trigeminal autonomic cephalgias features like facial flushing, rhinorrhea, conjunctival injection, or tearing. The specificity of headache timing can be remarkable; its colloquial name is "alarm clock headache."

The pathophysiology of hypnic headache is almost completely unknown. Like migraine, cluster headache, and the trigeminal autonomic cephalgias, hypnic headache has been reported arising from REM sleep, although, as with migraine and cluster headache, this association is far from universal. ${ }^{104-106}$ Another interesting point is the association of hypnic headache with the elderly. In terms of sleep architecture, stage IV sleep is attenuated or lost after age 60. Rather than being specifically associated with REM or other stages, it may be that hypnic headache is favored by the loss of deep sleep stages and the increased arousability that accompanies this change. Yet, in seeming contradiction, caffeine is a very effective treatment for hypnic headache (although it does not prevent hynic headache patients from going to sleep). ${ }^{103}$ An alternative hypothesis is that hypnic headache represents a primary headache disorder, such as migraine, whose clinical features and relationship to sleep have been changed by the aging process. 
Narcolepsy

Narcolepsy is thought to be due to a selective loss of orexinergic neurons in the lateral hypothalamus. ${ }^{40,107,108}$ These neurons are active in arousal as well as in the inhibition of REM sleep - their loss is thought to contribute to the disruption of sleep-wake transitions and dysregulation of REM activity that characterize narcolepsy. As discussed earlier, hypothalamic orexinergic projections to the vlPAG are also involved in reducing nociceptive activity in the trigeminal nucleus caudalis, suggesting a possible role in primary headaches.

The information on narcolepsy and headaches is, unfortunately, conflicting. Two studies by the same group, documenting a significantly increased prevalence of migraine in narcolepsy, are opposed by another study of similar size showing no significant difference in migraine prevalence. ${ }^{109-111}$ This latter study did show a significant increase in tension-type headache in patients with narcolepsy. Taken together, the studies do suggest an increased prevalence of headache in the narcoleptic population, but elucidation of the type of headache awaits more conclusive study.

\section{Obstructive Sleep Apnea}

The morning headache associated with obstructive sleep apnea (OSA) is likely of a different nature than those discussed so far, in that it is likely a secondary rather than a primary headache. The International Classification of Headache Disorders classifies sleep apnea headache as a headache due to a disorder of homeostasis, specifically as a result of hypoxemia or hypercapnia. And these headaches tend to be quite responsive to correction of the metabolic insult, namely treatment with continuous positive airway pressure (CPAP) or oxygen supplementation (reviewed in reference 4). But, from a pathophysiologic point of view this begs the question of how hypoxemia or hypercapnia causes headache. Surprisingly, little is known about this. One possibility is that the generalized intra- and extracranial vasodilatation caused by hypoxemia and hypercapnia ${ }^{112}$ is perceived as painful, ${ }^{17}$ likely due to activation of trigeminal nociceptors in the cranial vasculature. ${ }^{20}$ The reduced $\mathrm{pH}$ caused by hypercapnia can also activate nociceptive neurons ${ }^{113}$ and cause vasodilatation. ${ }^{114}$ Moreover, sudden and large increases in cerebral blood flow and volume can increase intracranial pressure, which puts traction on the pain-sensitive dura and dural sinuses. ${ }^{17}$ The high prevalence of obstructive sleep apnea in patients (especially men) with intracranial hypertension suggests that increases in intracranial pressure could play a significant role in the headache associated with sleep apnea. ${ }^{115}$

\section{A CLINICAL APPROACH TO HEADACHE AND SLEEP COMPLAINTS}

Given the extensive overlap between headache disorders and sleep disorders, it is clear that an evaluation of headache should include an evaluation of sleep, and vice versa. A standardized sleep questionnaire is very helpful in this regard. ${ }^{4}$ The information gained from this type of evaluation may be important for the diagnosis of headache and sleep disorders, to identify and modify interrelated triggers, and for the development of a therapy that optimizes concurrent management of headache and sleep symptoms. 


\section{Diagnosis}

A headache diagnosis should be established in parallel with any sleep disorder diagnosis, so that they can be addressed both jointly and independently. The timing of headache relative to sleep may be an important feature that leads to the diagnosis of cluster headache, hypnic headache, or headache associated with OSA. For migraine, yawning and fatigue preceding or during attacks and relief by sleep are extremely common features that may contribute to the diagnosis. Because fatigue may be one of the most debilitating features of migraine, identification of this symptom as part of the migraine symptom complex may be an important part of the therapeutic management of this disorder.

Conversely, there are multiple sleep-related disorders that may be identified in the course of evaluation of a patient with headache. Patients with headache should be queried for symptoms of insomnia, snoring, ${ }^{116}$ sleep apnea, ${ }^{117}$ restless legs syndrome, ${ }^{118,119}$ and sleepphase disturbances, each of which has been associated with different types of headache. Patients with intracranial hypertension, particularly men, should be carefully evaluated for sleep apnea given the strong association between these two conditions. ${ }^{115}$ Formal polysomnography should be considered in headache patients in whom symptoms of these potentially associated sleep disorders are identified on thorough questioning.

Other important diagnostic considerations include identification of anxiety and depression, comorbid conditions for both headache and sleep disorders that may influence each of them. However, although it is important to address anxiety and mood disorders as comorbid conditions, it should not be assumed that sleep disorders are simply a direct consequence of these conditions. Examination of the association between sleep disturbance and migraine indicates that it is independent of anxiety and mood disorders. ${ }^{120}$

Finally, a headache diagnosis should then be established in parallel with any sleep disorder diagnosis, so that they can be addressed both jointly and independently.

\section{Identification and Modification of Interrelated Triggers}

Patients with migraine commonly identify inadequate sleep, interrupted sleep, or excessive sleep as triggers for attacks. ${ }^{121}$ One study found that behavioral modification of sleep was beneficial in reducing the frequency of headache, and changing characteristics of headache from chronic to episodic migraine. ${ }^{122}$ There is no data to support specific sleep recommendations for episodic migraine or other headache disorders; therefore, a logical approach is to counsel patients to maintain good sleep hygiene that will help to avoid the commonly reported triggers. A consistent sleep schedule that avoids either too little or too much sleep, avoidance of daytime naps, and avoidance of conditions that lead to interrupted sleep are all reasonable recommendations for headache patients. Other lifestyle factors may have simultaneous and related exacerbating effects on headache and sleep disorders. Irregular timing of meals may be a significant trigger for headache attacks, and may also exacerbate sleep disorders. Emotional or physical stress is also commonly identified as a trigger for both headache and sleep disturbance. Finally, excessive or fluctuating caffeine intake may be an important exacerbating factor for headache and sleep disorders. For both, therefore, lifestyle modifications should focus on consistency of diet, exercise, and caffeine. 
A balanced diet with avoidance of skipped meals, routine aerobic exercise, and regular small amounts of caffeine (if any), are simple measures that are relatively easy to accomplish, and may have a significant beneficial impact on the headache and sleep disorders.

Examination of medications as potential exacerbating factors is also important. Medications such as nasal decongestants, stimulants used for the treatment of attention deficit disorder, and activating antidepressants may all have an adverse effect on headache and sleep. Some hypnotics used for treatment of insomnia may also cause or worsen headache. Headache is a relatively commonly reported adverse symptom of zolpidem and zaleplon in clinical studies. ${ }^{123-125}$ Although in most of the clinical trials the occurrence of headache was not statistically different in patients receiving zolpidem or zaleplon versus placebo, these and other hypnotics should be considered as potential exacerbating factors in patients with headache.

\section{Integrated Treatment}

In some cases, specific treatment of the headache disorder will ameliorate the associated sleep disorder, or vice versa. For example, abortive or preventive therapy of migraine or cluster headache may reduce associated insomnia or fragmentation of sleep. Specific treatment of sleep apnea may effectively relieve associated chronic headache. In other cases, it may be appropriate to choose therapy that simultaneously treats both headache and sleep disorders. The use of amitriptyline as preventive therapy for migraine, although not approved by the Food and Drug Administration (FDA), is supported by high-quality evidence. ${ }^{126}$ Such evidence is lacking regarding the use of amitriptyline for isolated sleep disorders; nevertheless, it has been shown to promote sleep in patients with chronic pain conditions and mood disorders. ${ }^{127-129}$ Thus, amitriptyline may be a reasonable choice in a patient with both migraine and insomnia or fragmented sleep. There is also limited evidence for the efficacy of melatonin as preventive therapy for both migraine and cluster headache (see above), as well as for treatment of insomnia. ${ }^{130}$ Given its generally excellent tolerability, melatonin is a safe nonprescription approach that may be of some benefit for patients with concurrent headache and sleep disturbance.

\section{CONCLUSIONS}

Much remains to be discovered about both sleep and headache disorders and their interactions, but some tentative conclusions can be drawn about their mechanisms. Anatomic evidence suggests several areas in the brainstem and diencephalon where processes integral to headache and sleep interact: the most prominent of these are the ventrolateral periaqueductal gray and the posterior hypothalamus. Physiologic data suggests the involvement of adenosine, melatonin, and orexin in both sets of disorders, and although the evidence is weaker, a dysregulation of either REM sleep or underlying arousal mechanisms in many headache disorders. Preliminary data from transgenic models suggest that derangement of sleep is common to two different forms of familial migraine. On the clinical side, the conclusions can be more certain: treatment of headache cannot be optimized without attention to sleep hygiene and sleep disorders. A sleep questionnaire should be part of every chronic headache evaluation, sleep studies should be considered for certain patient 
groups, and inquiry about headaches should figure prominently in the evaluation of all sleep disorders.

\section{References}

1. Rains JC, Poceta JS. Headache and sleep disorders: review and clinical implications for headache management. Headache. 2006; 46(9):1344-1363. [PubMed: 17040332]

2. Dodick DW, Eross EJ, Parish JM, Silber M. Clinical, anatomical, and physiologic relationship between sleep and headache. Headache. 2003; 43(3):282-292. [PubMed: 12603650]

3. Rains JC, Poceta JS, Penzien DB. Sleep and headaches. Curr Neurol Neurosci Rep. 2008; 8(2):167175. [PubMed: 18460287]

4. Rains JC, Poceta JS. Sleep-related headache syndromes. Semin Neurol. 2005; 25(1):69-80. [PubMed: 15798939]

5. Jennum P, Jensen R. Sleep and headache. Sleep Med Rev. 2002; 6(6):471-479. [PubMed: 12505479]

6. Saper CB, Scammell TE, Lu J. Hypothalamic regulation of sleep and circadian rhythms. Nature. 2005; 437(7063):1257-1263. [PubMed: 16251950]

7. Fuller PM, Gooley JJ, Saper CB. Neurobiology of the sleep-wake cycle: sleep architecture, circadian regulation, and regulatory feedback. J Biol Rhythms. 2006; 21(6):482-493. [PubMed: 17107938]

8. Porkka-Heiskanen T, Strecker RE, Thakkar M, Bjorkum AA, Greene RW, McCarley RW. Adenosine: a mediator of the sleep-inducing effects of prolonged wakefulness. Science. 1997; 276(5316):1265-1268. [PubMed: 9157887]

9. Aston-Jones G, Chen S, Zhu Y, Oshinsky ML. A neural circuit for circadian regulation of arousal. Nat Neurosci. 2001; 4(7):732-738. [PubMed: 11426230]

10. Lu J, Sherman D, Devor M, Saper CB. A putative flip-flop switch for control of REM sleep. Nature. 2006; 441(7093):589-594. [PubMed: 16688184]

11. Craig ADB. Pain mechanisms: labeled lines versus convergence in central processing. Annu Rev Neurosci. 2003; 26:1-30. [PubMed: 12651967]

12. Saper CB. The central autonomic nervous system: conscious visceral perception and autonomic pattern generation. Annu Rev Neurosci. 2002; 25:433-469. [PubMed: 12052916]

13. Benarroch EE. Pain-autonomic interactions. Neurol Sci. 2006; 27(Suppl 2):S130-S133. [PubMed: 16688616]

14. Raskin NH, Hosobuchi Y, Lamb S. Headache may arise from perturbation of brain. Headache. 1987; 27(8):416-420. [PubMed: 3667258]

15. Ostrowsky K, Magnin M, Ryvlin P, Isnard J, Guenot M, Mauguière F. Representation of pain and somatic sensation in the human insula: a study of responses to direct electrical cortical stimulation. Cereb Cortex. 2002; 12(4):376-385. [PubMed: 11884353]

16. Keller JT, Saunders MC, Beduk A, Jollis JG. Innervation of the posterior fossa dura of the cat. Brain Res Bull. 1985; 14(1):97-102. [PubMed: 3872702]

17. Ray B, Wolff H. Experimental studies on headache: pain-sensitive structures of the head and their significance in headache. Arch Surg. 1940; 41(4):813-856.

18. Ter Horst GJ, Meijler WJ, Korf J, Kemper RH. Trigeminal nociception-induced cerebral Fos expression in the conscious rat. Cephalalgia. 2001; 21(10):963-975. [PubMed: 11843868]

19. Malick A, Burstein R. Cells of origin of the trigeminohypothalamic tract in the rat. J Comp Neurol. 1998; 400(1):125-144. [PubMed: 9762871]

20. Edvinsson L, Uddman R. Neurobiology in primary headaches. Brain Res Brain Res Rev. 2005; 48(3):438-456. [PubMed: 15914251]

21. Porreca F, Ossipov MH, Gebhart GF. Chronic pain and medullary descending facilitation. Trends Neurosci. 2002; 25(6):319-325. [PubMed: 12086751]

22. Porreca, F. Presidential symposium: Descending facilitation. Paper presented at: 50th Annual Scientific Meeting of the American Headache Society; June 26-29, 2008; Boston, MA. 
23. Burstein R, Jakubowski M. Unitary hypothesis for multiple triggers of the pain and strain of migraine. J Comp Neurol. 2005; 493(1):9-14. [PubMed: 16258903]

24. Holland, P., Akerman, S., Lasalandra, M., Goadsby, P. Orexin A antinociceptive effects in the ventrolateral periaqueductal gray are blocked by 5HT 1B/D receptor antagonism (abstract). Abstract presented at: 133rd Annual Meeting of the American Neurological Association; September 21-24, 2008; Salt Lake City, UT.

25. Holland PR, Akerman S, Goadsby PJ. Modulation of nociceptive dural input to the trigeminal nucleus caudalis via activation of the orexin 1 receptor in the rat. Eur J Neurosci. 2006; 24(10): 2825-2833. [PubMed: 17156207]

26. Holland PR, Akerman S, Goadsby PJ. Orexin 1 receptor activation attenuates neurogenic dural vasodilation in an animal model of trigeminovascular nociception. J Pharmacol Exp Ther. 2005; 315(3):1380-1385. [PubMed: 16160082]

27. Weiller C, May A, Limmroth V, et al. Brain stem activation in spontaneous human migraine attacks. Nat Med. 1995; 1(7):658-660. [PubMed: 7585147]

28. Afridi S, Goadsby PJ. New onset migraine with a brain stem cavernous angioma. J Neurol Neurosurg Psychiatry. 2003; 74(5):680-682. [PubMed: 12700321]

29. Rocca MA, Ceccarelli A, Falini A, et al. Brain gray matter changes in migraine patients with T2visible lesions: a 3-T MRI study. Stroke. 2006; 37(7):1765-1770. [PubMed: 16728687]

30. Veloso F, Kumar K, Toth C. Headache secondary to deep brain implantation. Headache. 1998; 38(7):507-515. [PubMed: 15613166]

31. May A, Bahra A, Büchel C, Frackowiak RS, Goadsby PJ. Hypothalamic activation in cluster headache attacks. Lancet. 1998; 352(9124):275-278. [PubMed: 9690407]

32. Matharu MS, Cohen AS, Frackowiak RSJ, Goadsby PJ. Posterior hypothalamic activation in paroxysmal hemicrania. Ann Neurol. 2006; 59(3):535-545. [PubMed: 16489610]

33. Sprenger T, Valet M, Platzer S, Pfaffenrath V, Steude U, Tolle TR. SUNCT: bilateral hypothalamic activation during headache attacks and resolving of symptoms after trigeminal decompression. Pain. 2005; 113(3):422-426. [PubMed: 15661452]

34. May A, Bahra A, Büchel C, Turner R, Goadsby PJ. Functional magnetic resonance imaging in spontaneous attacks of SUNCT: short-lasting neuralgiform headache with conjunctival injection and tearing. Ann Neurol. 1999; 46(5):791-794. [PubMed: 10554000]

35. Denuelle M, Fabre N, Payoux P, Chollet F, Geraud G. Hypothalamic activation in spontaneous migraine attacks. Headache. 2007; 47(10):1418-1426. [PubMed: 18052951]

36. Hsieh JC, Ståhle-Bäckdahl M, Hägermark O, Stone-Elander S, Rosenquist G, Ingvar M. Traumatic nociceptive pain activates the hypothalamus and the periaqueductal gray: a positron emission tomography study. Pain. 1996; 64(2):303-314. [PubMed: 8740608]

37. Jacquet YF, Lajtha A. Morphine action at central nervous system sites in rat: analgesia or hyperalgesia depending on site and dose. Science. 1973; 182(4111):490-492. [PubMed: 4582903]

38. Leone M, Proietti Cecchini A, Franzini A, et al. Lessons from 8 years' experience of hypothalamic stimulation in cluster headache. Cephalalgia. 2008; 28(7):787-797. discussion 798. [PubMed: 18547215]

39. Xie X, Wisor JP, Hara J, et al. Hypocretin/orexin and nociceptin/orphanin FQ coordinately regulate analgesia in a mouse model of stress-induced analgesia. J Clin Invest. 2008; 118(7):2471-2481. [PubMed: 18551194]

40. Thannickal TC, Moore RY, Nienhuis R, et al. Reduced number of hypocretin neurons in human narcolepsy. Neuron. 2000; 27(3):469-474. [PubMed: 11055430]

41. Jacobson KA, Gao ZG. Adenosine receptors as therapeutic targets. Nat Rev Drug Discov. 2006; 5(3):247-264. [PubMed: 16518376]

42. Porkka-Heiskanen T, Alanko L, Kalinchuk A, Stenberg D. Adenosine and sleep. Sleep Med Rev. 2002; 6(4):321-332. [PubMed: 12531135]

43. Landolt HP. Sleep homeostasis: a role for adenosine in humans? Biochem Pharmacol. 2008; 75(11):2070-2079. [PubMed: 18384754]

44. Satoh S, Matsumura H, Suzuki F, Hayaishi O. Promotion of sleep mediated by the A2a-adenosine receptor and possible involvement of this receptor in the sleep induced by prostaglandin D2 in rats. Proc Natl Acad Sci U S A. 1996; 93(12):5980-5984. [PubMed: 8650205] 
45. Rétey JV, Adam M, Honegger E, et al. A functional genetic variation of adenosine deaminase affects the duration and intensity of deep sleep in humans. Proc Natl Acad Sci U S A. 2005; 102(43):15676-15681. [PubMed: 16221767]

46. De Lander GE, Keil GJ II. Antinociception induced by intrathecal coadministration of selective adenosine receptor and selective opioid receptor agonists in mice. J Pharmacol Exp Ther. 1994; 268(2):943-951. [PubMed: 8114009]

47. Wu WP, Hao JX, Halldner L, et al. Increased nociceptive response in mice lacking the adenosine A1 receptor. Pain. 2005; 113(3):395-404. [PubMed: 15661449]

48. Goadsby PJ, Hoskin KL, Storer RJ, Edvinsson L, Connor HE. Adenosine A1 receptor agonists inhibit trigeminovascular nociceptive transmission. Brain. 2002; 125(Pt 6):1392-1401. [PubMed: 12023327]

49. Giffin NJ, Kowacs F, Libri V, Williams P, Goadsby PJ, Kaube H. Effect of the adenosine A1 receptor agonist GR79236 on trigeminal nociception with blink reflex recordings in healthy human subjects. Cephalalgia. 2003; 23(4):287-292. [PubMed: 12716347]

50. Gan TJ, Habib AS. Adenosine as a non-opioid analgesic in the perioperative setting. Anesth Analg. 2007; 105(2):487-494. [PubMed: 17646510]

51. Ferré S, Diamond I, Goldberg SR, et al. Adenosine A2A receptors in ventral striatum, hypothalamus and nociceptive circuitry implications for drug addiction, sleep and pain. Prog Neurobiol. 2007; 83(5):332-347. [PubMed: 17532111]

52. Shapiro RE. Caffeine and headaches. Curr Pain Headache Rep. 2008; 12(4):311-315. [PubMed: 18625110]

53. Kruuse C, Lassen LH, Iversen HK, Oestergaard S, Olesen J. Dipyridamole may induce migraine in patients with migraine without aura. Cephalalgia. 2006; 26(8):925-933. [PubMed: 16886928]

54. Brown SG, Waterer GW. Migraine precipitated by adenosine. Med J Aust. 1995; 162(7):389-391. 391.

55. Esquisatto LC, Costa SK, Camargo EA, et al. The plasma protein extravasation induced by adenosine and its analogues in the rat dorsal skin: evidence for the involvement of capsaicin sensitive primary afferent neurones and mast cells. Br J Pharmacol. 2001; 134(1):108-115. [PubMed: 11522602]

56. Guieu R, Sampiéri F, Bechis G, Rochat H. Use of HPLC to measure circulating adenosine levels in migrainous patients. Clin Chim Acta. 1994; 227(1-2):185-194. [PubMed: 7955415]

57. Guieu R, Devaux C, Henry H, et al. Adenosine and migraine. Can J Neurol Sci. 1998; 25(1):55-58. [PubMed: 9532282]

58. Hohoff C, Marziniak M, Lesch KP, Deckert J, Sommer C, Mössner R. An adenosine A2A receptor gene haplotype is associated with migraine with aura. Cephalalgia. 2007; 27(2):177-181. [PubMed: 17257240]

59. Arendt J, Skene DJ. Melatonin as a chronobiotic. Sleep Med Rev. 2005; 9(1):25-39. [PubMed: 15649736]

60. Chazot G, Claustrat B, Brun J, Jordan D, Sassolas G, Schott B. A chronobiological study of melatonin, cortisol growth hormone and prolactin secretion in cluster headache. Cephalalgia. 1984; 4(4):213-220. [PubMed: 6518501]

61. Waldenlind E, Gustafsson SA, Ekbom K, Wetterberg L. Circadian secretion of cortisol and melatonin in cluster headache during active cluster periods and remission. J Neurol Neurosurg Psychiatry. 1987; 50(2):207-213. [PubMed: 3572435]

62. Leone M, Frediani F, D'Amico D, et al. Dexamethasone suppression test, melatonin and TRH-test in cluster headache. Ital J Neurol Sci. 1992; 13(3):227-232. [PubMed: 1624279]

63. Leone M, Lucini V, D’Amico D, et al. Twenty-four-hour melatonin and cortisol plasma levels in relation to timing of cluster headache. Cephalalgia. 1995; 15(3):224-229. [PubMed: 7553813]

64. Claustrat B, Loisy C, Brun J, Beorchia S, Arnaud JL, Chazot G. Nocturnal plasma melatonin levels in migraine: a preliminary report. Headache. 1989; 29(4):242-245. [PubMed: 2714976]

65. Murialdo G, Fonzi S, Costelli P, et al. Urinary melatonin excretion throughout the ovarian cycle in menstrually related migraine. Cephalalgia. 1994; 14(3):205-209. [PubMed: 7954740]

66. Claustrat B, Brun J, Chiquet C, Chazot G, Borson-Chazot F. Melatonin secretion is supersensitive to light in migraine. Cephalalgia. 2004; 24(2):128-133. [PubMed: 14728708] 
67. Leone M, D'Amico D, Moschiano F, Fraschini F, Bussone G. Melatonin versus placebo in the prophylaxis of cluster headache: a double-blind pilot study with parallel groups. Cephalalgia. 1996; 16(7):494-496. [PubMed: 8933994]

68. Vogler B, Rapoport AM, Tepper SJ, Sheftell F, Bigal ME. Role of melatonin in the pathophysiology of migraine: implications for treatment. CNS Drugs. 2006; 20(5):343-350. [PubMed: 16696576]

69. Shapiro RE, Waheed W, Nagle K. A novel familial syndrome of migraine with aura, flushing spells, myalgias, asthma, and the advanced sleep phase syndrome. Cephalalgia. 1999; 19:424. (Abstract).

70. Jones CR, Campbell SS, Zone SE, et al. Familial advanced sleep-phase syndrome: A short-period circadian rhythm variant in humans. Nat Med. 1999; 5(9):1062-1065. [PubMed: 10470086]

71. Xu Y, Padiath QS, Shapiro RE, et al. Functional consequences of a CKIdelta mutation causing familial advanced sleep phase syndrome. Nature. 2005; 434(7033):640-644. [PubMed: 15800623]

72. Brennan K, Beltran-Parrazal L, Lopez-Valdes H, et al. Reduced threshold for cortical spreading depression in mice transgenic for human CK1 $\delta$ T44A. Headache. 2006; 46(5):840. (Abstract).

73. Bolay H, Reuter U, Dunn AK, Huang Z, Boas DA, Moskowitz MA. Intrinsic brain activity triggers trigeminal meningeal afferents in a migraine model. Nat Med. 2002; 8(2):136-142. [PubMed: 11821897]

74. Bates, E. Defining the role of CK1 delta in migraine with aura. Paper presented at: 50th Annual Scientific Meeting of the American Headache Society; June 26-29, 2008; Boston, MA.

75. Albus H, Deboer T, Ferrari M, et al. FHM1 R192Q Cacna1a mutant mice show enhanced adjustment to advanced shifts of the light-dark cycle: a molecular basis to chronobiology in migraine? Cephalalgia. 2007; 27(6):624. (Abstract).

76. Martin VT, Behbehani M. Ovarian hormones and migraine headache: understanding mechanisms and pathogenesis — part 2. Headache. 2006; 46(3):365-386. [PubMed: 16618254]

77. Cugini P, Romit A, Di Palma L, Giacovazzo M. Common migraine as a weekly and seasonal headache. Chronobiol Int. 1990; 7(5-6):467-469. [PubMed: 2097080]

78. Alstadhaug KB, Salvesen R, Bekkelund SI. Seasonal variation in migraine. Cephalalgia. 2005; 25(10):811-816. [PubMed: 16162258]

79. Alstadhaug KB, Bekkelund S, Salvesen R. Circannual periodicity of migraine? Eur J Neurol. 2007; 14(9):983-988. [PubMed: 17718689]

80. Dexter JD, Riley TL. Studies in nocturnal migraine. Headache. 1975; 15(1):51-62. [PubMed: 1132991]

81. Solomon GD. Circadian rhythms and migraine. Cleve Clin J Med. 1992; 59(3):326-329. [PubMed: 1516220]

82. Fox AW, Davis RL. Migraine chronobiology. Headache. 1998; 38(6):436-441. [PubMed: 9664747]

83. Alstadhaug K, Salvesen R, Bekkelund S. 24-hour distribution of migraine attacks. Headache. 2008; 48(1):95-100. [PubMed: 18184291]

84. Hsu LK, Crisp AH, Kalucy RS, et al. Early morning migraine. Nocturnal plasma levels of catecholamines, tryptophan, glucose, and free fatty acids and sleep encephalographs. Lancet. 1977; 1(8009):447-451. [PubMed: 65562]

85. Dexter JD, Weitzman ED. The relationship of nocturnal headaches to sleep stage patterns. Neurology. 1970; 20(5):513-518. [PubMed: 4314825]

86. Dexter JD. The relationship between stage III + IV + REM sleep and arousals with migraine. Headache. 1979; 19(7):364-369. [PubMed: 229086]

87. Göder R, Fritzer G, Kapsokalyvas A, et al. Polysomnographic findings in nights preceding a migraine attack. Cephalalgia. 2001; 21(1):31-37. [PubMed: 11298661]

88. Drake ME Jr, Pakalnis A, Andrews JM, Bogner JE. Nocturnal sleep recording with cassette EEG in chronic headaches. Headache. 1990; 30(9):600-603. [PubMed: 2262315]

89. Vendrame M, Kaleyias J, Valencia I, Legido A, Kothare SV. Polysomnographic findings in children with headaches. Pediatr Neurol. 2008; 39(1):6-11. [PubMed: 18555166] 
90. Della Marca G, Vollono C, Rubino M, Di Trapani G, Mariotti P, Tonali PA. Dysfunction of arousal systems in sleep-related migraine without aura. Cephalalgia. 2006; 26(7):857-864. [PubMed: 16776702]

91. Bruni O, Russo PM, Violani C, Guidetti V. Sleep and migraine: an actigraphic study. Cephalalgia. 2004; 24(2):134-139. [PubMed: 14728709]

92. Russell D. Cluster headache: severity and temporal profiles of attacks and patient activity prior to and during attacks. Cephalalgia. 1981; 1(4):209-216. [PubMed: 7347624]

93. Pfaffenrath V, Pöllmann W, Rüther E, Lund R, Hajak G. Onset of nocturnal attacks of chronic cluster headache in relation to sleep stages. Acta Neurol Scand. 1986; 73(4):403-407. [PubMed: 3727916]

94. Sprenger T, Boecker H, Tolle TR, Bussone G, May A, Leone M. Specific hypothalamic activation during a spontaneous cluster headache attack. Neurology. 2004; 62(3):516-517. [PubMed: 14872051]

95. May A, Ashburner J, Büchel C, et al. Correlation between structural and functional changes in brain in an idiopathic headache syndrome. Nat Med. 1999; 5(7):836-838. [PubMed: 10395332]

96. Lodi R, Pierangeli G, Tonon C, et al. Study of hypothalamic metabolism in cluster headache by proton MR spectroscopy. Neurology. 2006; 66(8):1264-1266. [PubMed: 16636250]

97. Manzoni GC, Terzano MG, Moretti G, Cocchi M. Clinical observations on 76 cluster headache cases. Eur Neurol. 1981; 20(2):88-94. [PubMed: 7215402]

98. Rainero I, Gallone S, Valfrè W, et al. A polymorphism of the hypocretin receptor 2 gene is associated with cluster headache. Neurology. 2004; 63(7):1286-1288. [PubMed: 15477554]

99. Rainero I, Rubino E, Valfrè W, et al. Association between the G1246A polymorphism of the hypocretin receptor 2 gene and cluster headache: a meta-analysis. J Headache Pain. 2007; 8(3): 152-156. [PubMed: 17563843]

100. May A, Bahra A, Büchel C, Turner R, Goadsby PJ. Functional magnetic resonance imaging in spontaneous attacks of SUNCT: short-lasting neuralgiform headache with conjunctival injection and tearing. Ann Neurol. 1999; 46(5):791-794. [PubMed: 10554000]

101. Matharu MS, Cohen AS, Frackowiak RSJ, Goadsby PJ. Posterior hypothalamic activation in paroxysmal hemicrania. Ann Neurol. 2006; 59(3):535-545. [PubMed: 16489610]

102. Goadsby PJ, Cittadini E, Burns B, Cohen AS. Trigeminal autonomic cephalalgias: diagnostic and therapeutic developments. Curr Opin Neurol. 2008; 21(3):323-330. [PubMed: 18451717]

103. Evers S, Goadsby PJ. Hypnic headache: clinical features, pathophysiology, and treatment. Neurology. 2003; 60(6):905-909. [PubMed: 12654950]

104. Dodick DW. Polysomnography in hypnic headache syndrome. Headache. 2000; 40(9):748-752. [PubMed: 11091295]

105. Evers S, Rahmann A, Schwaag S, Lüdemann P, Husstedt IW. Hypnic headache - the first German cases including polysomnography. Cephalalgia. 2003; 23(1):20-23. [PubMed: 12534575]

106. Liang JF, Fuh JL, Yu HY, Hsu CY, Wang SJ. Clinical features, polysomnography and outcome in patients with hypnic headache. Cephalalgia. 2008; 28(3):209-215. [PubMed: 18254891]

107. Nishino S, Ripley B, Overeem S, Lammers GJ, Mignot E. Hypocretin (orexin) deficiency in human narcolepsy. Lancet. 2000; 355(9197):39-40. [PubMed: 10615891]

108. Peyron C, Faraco J, Rogers W, et al. A mutation in a case of early onset narcolepsy and a generalized absence of hypocretin peptides in human narcoleptic brains. Nat Med. 2000; 6(9): 991-997. [PubMed: 10973318]

109. Dahmen N, Querings K, Grün B, Bierbrauer J. Increased frequency of migraine in narcoleptic patients. Neurology. 1999; 52(6):1291-1293. [PubMed: 10214764]

110. Dahmen N, Kasten M, Wieczorek S, Gencik M, Epplen JT, Ullrich B. Increased frequency of migraine in narcoleptic patients: a confirmatory study. Cephalalgia. 2003; 23(1):14-19.

[PubMed: 12534574]

111. The DMKG Study Group. Migraine and idiopathic narcolepsy-a case-control study. Cephalalgia. 2003; 23(8):786-789. [PubMed: 14510924] 
112. Reis DJ, Golanov EV, Galea E, Feinstein DL. Central neurogenic neuroprotection: central neural systems that protect the brain from hypoxia and ischemia. Ann N Y Acad Sci. 1997; 835:168186. [PubMed: 9616772]

113. Steen KH, Reeh PW. Sustained graded pain and hyperalgesia from harmless experimental tissue acidosis in human skin. Neurosci Lett. 1993; 154(1-2):113-116. [PubMed: 8361622]

114. Lindauer U, Vogt J, Schuh-Hofer S, Dreier JP, Dirnagl U. Cerebrovascular vasodilation to extraluminal acidosis occurs via combined activation of ATP-sensitive and $\mathrm{Ca} 2+$-activated potassium channels. J Cereb Blood Flow Metab. 2003; 23(10):1227-1238. [PubMed: 14526233]

115. Bruce BB, Kedar S, Van Stavern GP, et al. Idiopathic intracranial hypertension in men. Neurology. 2009; 72(4):304-309. [PubMed: 18923135]

116. Scher AI, Lipton RB, Stewart WF. Habitual snoring as a risk factor for chronic daily headache. Neurology. 2003; 60(8):1366-1368. [PubMed: 12707447]

117. Mitsikostas DD, Vikelis M, Viskos A. Refractory chronic headache associated with obstructive sleep apnoea syndrome. Cephalalgia. 2008; 28(2):139-143. [PubMed: 17999682]

118. Rhode AM, Hösing VG, Happe S, Biehl K, Young P, Evers S. Comorbidity of migraine and restless legs syndrome-a case-control study. Cephalalgia. 2007; 27(11):1255-1260. [PubMed: 17888079]

119. d'Onofrio F, Bussone G, Cologno D, et al. Restless legs syndrome and primary headaches: a clinical study. Neurol Sci. 2008; 29(Suppl 1):S169-S172. [PubMed: 18545926]

120. Vgontzas A, Cui L, Merikangas KR. Are sleep difficulties associated with migraine attributable to anxiety and depression? Headache. 2008; 48(10):1451-1459. [PubMed: 18624714]

121. Kelman L. The triggers or precipitants of the acute migraine attack. Cephalalgia. 2007; 27(5): 394-402. [PubMed: 17403039]

122. Calhoun AH, Ford S. Behavioral sleep modification may revert transformed migraine to episodic migraine. Headache. 2007; 47(8):1178-1183. [PubMed: 17883522]

123. Dorsey CM, Lee KA, Scharf MB. Effect of zolpidem on sleep in women with perimenopausal and postmenopausal insomnia: a 4-week, randomized, multicenter, double-blind, placebo-controlled study. Clin Ther. 2004; 26(10):1578-1586. [PubMed: 15598474]

124. Krystal AD, Erman M, Zammit GK, Soubrane C, Roth T. ZOLONG Study Group. Long-term efficacy and safety of zolpidem extended-release $12.5 \mathrm{mg}$, administered 3 to 7 nights per week for 24 weeks, in patients with chronic primary insomnia: a 6-month, randomized, double-blind, placebo-controlled, parallel-group, multicenter study. Sleep. 2008; 31(1):79-90. [PubMed: 18220081]

125. Weitzel KW, Wickman JM, Augustin SG, Strom JG. Zaleplon: a pyrazolopyrimidine sedativehypnotic agent for the treatment of insomnia. Clin Ther. 2000; 22(11):1254-1267. [PubMed: 11117652]

126. Silberstein SD, Goadsby PJ. Migraine: preventive treatment. Cephalalgia. 2002; 22(7):491-512. [PubMed: 12230591]

127. Hannonen P, Malminiemi K, Yli-Kerttula U, Isomeri R, Roponen P. A randomized, double-blind, placebo-controlled study of moclobemide and amitriptyline in the treatment of fibromyalgia in females without psychiatric disorder. Br J Rheumatol. 1998; 37(12):1279-1286. [PubMed: 9973149]

128. Versiani M, Ontiveros A, Mazzotti G, et al. Fluoxetine versus amitriptyline in the treatment of major depression with associated anxiety (anxious depression): a double-blind comparison. Int Clin Psychopharmacol. 1999; 14(6):321-327. [PubMed: 10565798]

129. Casper RC, Katz MM, Bowden CL, Davis JM, Koslow SH, Hanin I. The pattern of physical symptom changes in major depressive disorder following treatment with amitriptyline or imipramine. J Affect Disord. 1994; 31(3):151-164. [PubMed: 7963067]

130. Brzezinski A, Vangel MG, Wurtman RJ, et al. Effects of exogenous melatonin on sleep: a metaanalysis. Sleep Med Rev. 2005; 9(1):41-50. [PubMed: 15649737] 


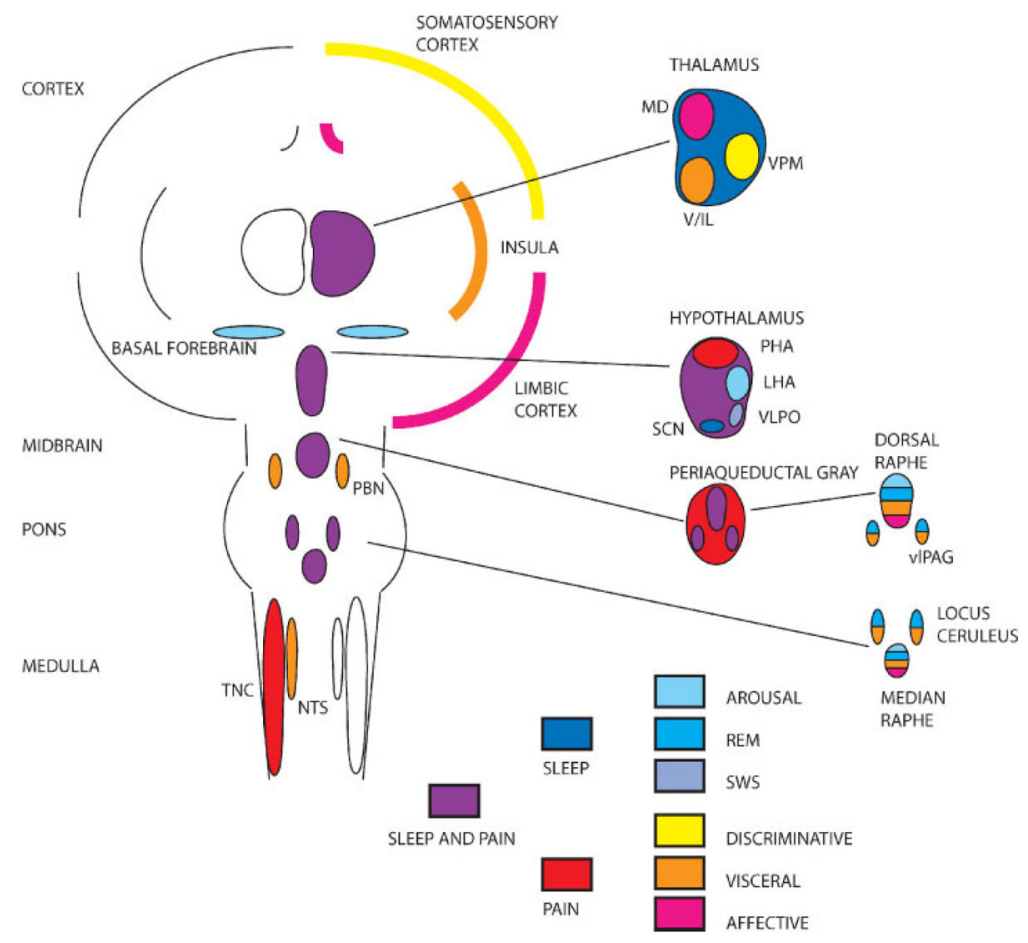

Figure 1.

Shared anatomy of headache and sleep. Simplified schematic shows cortical, subcortical, and brainstem structures involved in the regulation of nociception and sleep. Structures are color-coded (see key at bottom of schematic). Headache. Nociceptive inputs from craniofacial regions are collected at the trigeminal nucleus caudalis (TNC) and send collaterals to the nucleus of the solitary tract (NTS) and parabrachial nucleus (PBN), and hypothalamus, allowing integration of nociceptive inputs into autonomic control circuits. Ascending nociceptive information relays through the thalamus on the way to somatosensory, visceral, and limbic cortex. The latter two cortices also have direct reciprocal connections with brainstem and diencephalic autonomic control regions. Sleep and arousal. Sleep and arousal are controlled by a widely distributed brainstem and diencephalic network, with basal forebrain and cholinergic nuclei favoring arousal and the ventrolateral preoptic hypothalamus (VLPO) favoring sleep. The thalamus is a crucial relay whose output, and thus cortical activity, depends on arousal-related inputs. Shared structures. Several of the structures involved in nociception and sleep are shared, the most prominent of which are the ventrolateral periaqueductal gray (vlPAG) and the posterior and lateral hypothalamus (PHA, LHA). See color coding and text for details. LHA, lateral hypothalamus; MD, mediodorsal nucleus of thalamus; SCN, suprachiasmatic nucleus of hypothalamus; V/IL, ventral tier and intralaminar thalamic nuclei; VPM, ventral posteromedial nucleus of thalamus; REM, rapid eye movement; SWS, slow wave sleep. 